\title{
Written Exam Cheating and Prevention and Detection Strategies: The Case Of DMU
}

\author{
Mengistu Anagaw (MEd) \\ Debre Markos, Ethiopia
}

\begin{abstract}
The study aimed at investigating exam cheating focusing on prevalence, methods and reasons for written exam cheating and prevention and detection strategies. To that end, quantitative (on the prevalence, factors and methods of exam cheating) and qualitative (the possible prevention and detection strategies) data were collected adopting a mixed methods sequential explanatory design. A total of 320 students ( $60 \%$ males, $40 \%$ females) responded to the questionnaire while 14 students participated in FGDs. The registrar director was also interviewed. Results indicated that more than $53.75 \%$, of students admitted to cheating in exams. Results also indicated that as student achievement increases from the lower category to the medium, incidences of cheating increases but decreases in the higher achievement category. The three most frequent cheating methods used by students were copying from another student by looking at his/her test paper, using electronic devices like phones as cheat aid and passing notes on which answers to questions are written. The least frequently used cheating methods are distracting invigilators to help others cheat, writing notes on body parts and writing notes on desks. Time pressure to prepare for an exam, hard courses, students own laziness, hard exams and poor invigilators vigilance are reported as the most compelling factors forcing students cheat during written exams. On the other end, cheating to cope with stress of studying, cheating because everybody does it and because of lack of study skills are reported as weak predictors. To prevent exam cheating, an integrated and continuous effort involving cheating prevention (before the exam), cheating detection (during the exam) and cheating data retention-archiving (after the exam) should be instigated by the university. Archiving exam cheating data would help in taking measures and preventing it in the first place. These would create an atmosphere where success by cheating is unlikely and futile.
\end{abstract}

Keywords: Exam cheating, exam cheating methods, exam cheating prevention\& detection strategies

DOI: $10.7176 / \mathrm{JEP} / 10-7-07$

Publication date:March $31^{\text {st }} 2019$

\section{INTRODUCTION}

Education is the foundation upon which physical and technological developments prosper. It is also a veritable tool in the development of a country. Education, however, may not have meaning without effective assessment. Thus, assessment is required to determine the standard and level of achievement of learners in an educational program.

Academic integrity is an issue of critical importance to educational assessment and has been gaining increased interest among scholars and practitioners in the last few decades. Though examination plays several roles in the teaching-learning process, cheating may jeopardize its effectiveness. Examinations are basic reasons to study, serve as a means of getting feedback and are measures for evaluating success of instructional delivery, selection, placement, and employment, but when an examination is abused, these roles of examinations cannot not be properly entertained (Mebratu Mulatu, 2014).

In addition to being unwanted, exam cheating leads to two basic problems at institutional level. As of Brimble and Stevenson- Clarke (2005), the first problem is that of 'equity and efficacy of instruction'. In other words, instructional effectiveness is not measured reliably if students cheat in the exam. The other problem is students reduce their potential of learning and will in future be less prepared for advanced study if they are cheating in exams. Moreover, there are evidences that exam cheating correlates with corruption at the latter ages (ibid).

As newly emerging institutions of higher learning, Ethiopian Universities are faced with a plethora of problems of which exam cheating is one. Desalegn and Berhan (2014) reported that self-reported cheating was found to be $19.8 \%$ in Hawasa University College of medicine and health sciences though they didn't uncover prevention and detection strategies. A study by Tefera T. \& Kinde G. (2010) reported about $82 \%$ of student respondents from Business and Education Faculties in Addis Ababa and Jimma Universities admit to have cheated and suggested qualitative studies to solicit in depth information from the participants that answers the why and how aspects. However, these studies didn't identify the frequently used methods of cheating in addition to the prevention and detection techniques.

In Debre Markos University, the prevalence, factors and methods of written exam cheating has not been empirically studied, yet complains regarding this malpractice were frequent. The number of students caught while copying from their classmates, from a cheat sheet or an electronically sent or stored source or other methods is not amenable. As of the researcher's personal observation, instructors from different departments often make efforts; for example, by darkening answer sheets and using codes, to prevent exam cheating. However, these efforts are 
not institutionalized and highly depend on the personal will and efforts of the instructors paving way for less strict invigilators allow students cheat. On top of that, measures taken on cheating can thrive only when practiced consistently and efficaciously though strategies to facilitate this are not established.

Thus, this study attempted to identify the factors that persuade students to cheat and invigorate possible strategies to prevent and detect exam cheating. In other words, the study tried to find out prevalence of written exam cheating, the basic cheating strategies students' use, the compelling factors influencing students, and the possible strategies that can be employed to prevent and detect exam cheating in the University in the 2008 E.C. academic year. Hence, the study has been devoted to address the following basic research questions.

\subsection{Objectives of the Study}

The purpose of this study is to assess factors that persuade students to cheat during classroom written examinations and recommend possible strategies to prevent and detect it. Specifically the study intended to:

1. assess the prevalence and severity of cheating during written exams of the University.

2. Identify the compelling factors that force students cheat during written exams.

3. identify the exam cheating strategies students' use.

4. devise exam cheating prevention and detection strategies.

\section{RESEARCH METHODOLOGY}

\subsection{Study Design}

The purpose of this study has been assessing the factors that persuade students to cheat and recommend possible strategies to prevent and detect it. Specifically, the study intends to identify prevalence of exam cheating, factors forcing students cheat, exam cheating strategies that students' use and devise prevention and detection strategies. This research purpose is best addressed using mixed methods sequential explanatory design (Creswell, 2011) where quantitative data (on the prevalence of cheating, factors that influence of exam cheating and exam cheating strategies) and qualitative (the possible prevention and detection strategies) were collected. Thus, the qualitative data collected through focus group discussion and interview refined and explained earlier quantitative data from the questionnaire.

\subsection{Population, Sampling Procedure and Sample Size}

According to Israel (2009) a sample size of 383 is representative with a 5\% margin of error and $95 \%$ confidence level when studying a population size of not exceeding 9000. But because exam cheating is an issue of illusions, the sampled number of students for this study were 463 regular undergraduate students from the colleges of Technology, Business and Economics, Natural and Computational and Bure Campus selected through the proportionate stratified sampling technique. However, the number of students who responded correctly and considered for analysis dropped to 320 which yields a $83.5 \%$ return rate adequate for analysis. The students were selected through the proportionate stratified technique inclusive of achievement groups, batches and departments from sampled colleges. Lottery techinique was used to determine achievement category when size for the section was less than three. Moreover, two FGDs involving students in both campuses was carried out. Registrar Director of the University was interviewed on the basis of findings from the questionnaire.

\subsection{Data Collection Instruments}

Data having the nature of quantitative and qualitative types was collected using the following tools.

\subsubsection{Questionnaire}

A self-reported questionnaire consisting of three sections was used to collect information from participants. The questionnaire was prepared by the researcher based on McCabes' (2003) Academic Integrity Survey. The first section of the questionnaire focused on demographic information of the respondents and their previous cheating experiences. The second included commonly used cheating methods and behaviors. Respondents were asked to indicate whether and how often they have cheated using either of the listed methods and rate how they feel about the severity of those offences. The last part asked students to rate the 20 factors that were assumed to influence students cheat on exams. Respondents were asked to determine the influence of each item using a five-point Likert scale that ranged from 1: very small effect to 5: very big effect. Respondents were guaranteed confidentiality, and the questionnaire was filled in anonymously with no identification information.

\subsubsection{Focus Group Discussion (FGD)}

A focus group discussion was carried out with selected students to corroborate findings from the questionnaire and find out ways to alleviate the problem based on suggestions from the horse's mouth. The number of students who participated in the FGD was six in Bure campus and eight in main campus selected purposively for accessibility.

\subsection{Data collection procedures}

The data collection has been carried out through the following procedures. First, participant students were 
identified via the above sampling procedures. The selected students were invited by the researcher and were briefed about purposes of the study and its ethical considerations. Cognizant of this, volunteering students were briefed further about how they have to respond to the questionnaire and its importance. After this, the questionnaire was administered in each department and responded by students. However, exam cheating records and documents are not systematically organized and recorded and hence not analyzed to avoid exclusion bias. Based on the findings from questionnaire, interview items for the registrar director were prepared. The researcher took notes during the interview. Moreover, the focus group discussion was carried out based on earlier findings to uncover possible solutions. The researcher moderated the FGD discussants in both campuses while taking notes.

\subsection{Data Analysis Techniques}

The data having quantitative nature is organized and analyzed through the use of SPSS (Statistical Package for Social Sciences) computer program. Hence, descriptive and inferential statistics is used for data summarization and presentation. Moreover, the qualitative data from FGD and interview is transcribed as it is found in the sources and analyzed thematically.

\section{RESULTS AND DISCUSSION}

The purpose of this study has been assessing factors that persuade students to cheat during written exams and recommend possible strategies to prevent and detect it. Specifically, the study intended to identify prevalence of exam cheating, factors forcing students cheat, exam cheating strategies that students' use and possible prevention and detection strategies.

Respondents were classified based on their college into four groups: Technology, CBE, CNCS and Bure Campus. As for achievement, student's SGPA was used to classify respondents to three groups: 1 to $<2,2$ to $<3$, and 3 to $\leq 4$. The four college groups, three achievement groups, and gender are used in the analysis of the results. Accordingly, more than $60 \%$ (194) of the participants were males and 40\% (126) were females. Achievement wise, $16.9 \%$ scored below $2.00,57.5$ were in between 2.00 and 3.00 while the remaining 25.6 scored above 3.00 . Nearly half of the participants, $46.3 \%$ (148) are from the college of technology while the remaining 20.6\% (66), 18.1\% (58) and 15\% (48) are from CBE, CNCS and Bure Campus, respectively. Hence, the interpretation of findings has to consider this demographic information.

\subsection{Prevalence of Cheating in Exams}

Percentages of students admitted to have cheated in exams by gender, college, and GPA are shown in Table 1. The overall percentage of students who admitted cheating in written exams in the semester was $53.75 \%$, indicating that cheating is widespread among the sampled students though lower than what Philip C. H. (2006) reported that globally about $60-70 \%$ admit cheating. However, this problem is less prevalent than what has been reported in Addis Ababa and Jimma universities (Tefera T. \& Kinde G., 2010). When considered gender wise, the difference in the percentage of cheating is not significant. More than $54 \%$ of male students admitted to have cheated slightly higher than about $53 \%$ of females though this result can be explained by different factors. Complimenting this, in the FGD carried out, participants didn't report gender and department as significant causes for cheating. Of the respondents who admitted cheating at least once, about 59\% have a Semester Grade Point Average of 2.00-3.00. This might be a reflection of the impact of students cheating to improve their grades. Concomitantly a participant from main campus, S2CBE reported that: The students cheat to improve their score. When they want to score a good grade but can't secure it on their own they try to cheat by different alternatives. And of course this can help them improve result.

Similarly more than $23.8 \%$ of those students whose score is above 3.00 admitted to have cheated at least once as compared to $27 \%$ of respondents who never cheated but scored like wise. 
Table 1. Percentage of Students Cheating in written Exams by Gender and SGPA

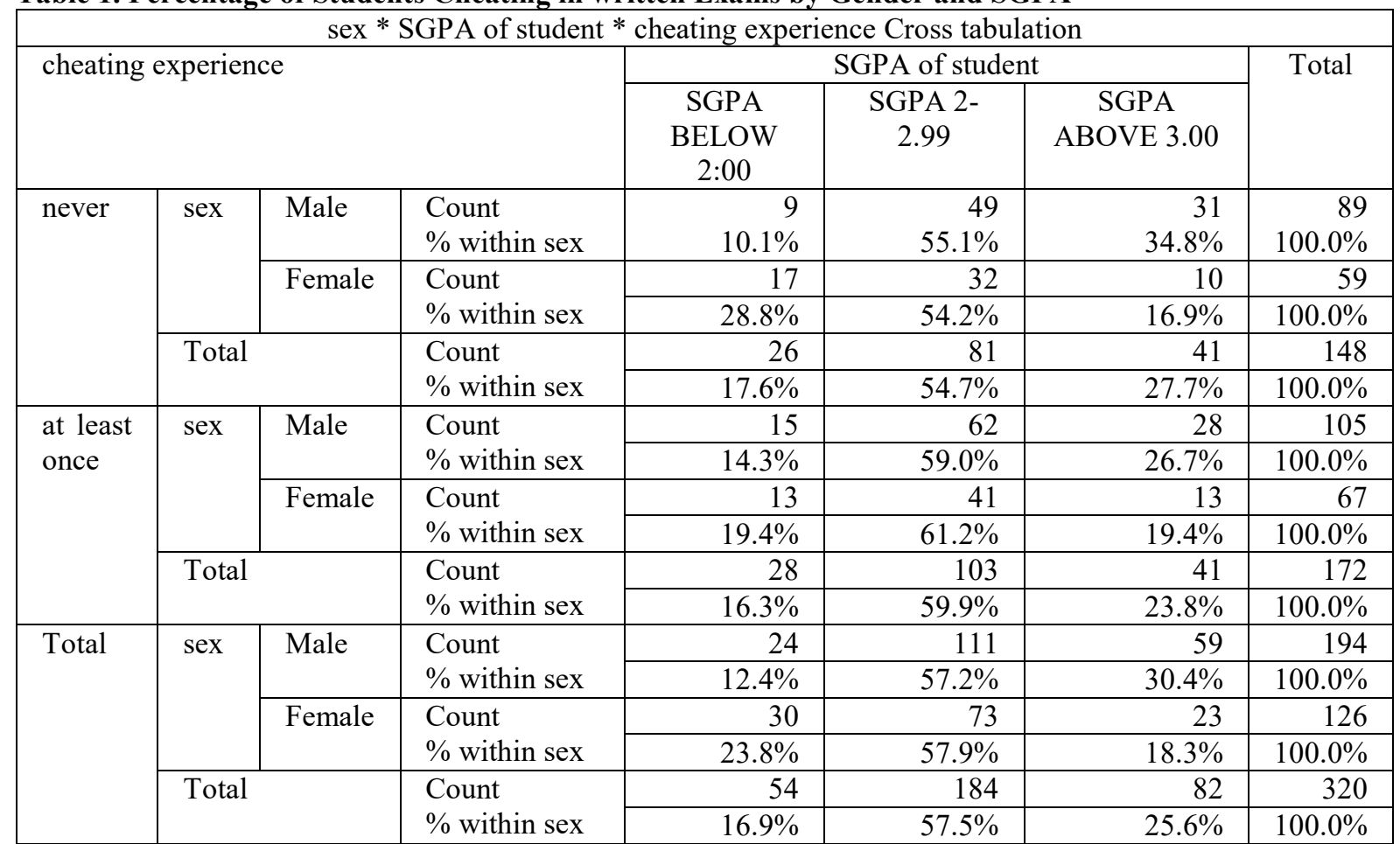

Table 2: cheating experience * saw others cheating Cross tabulation

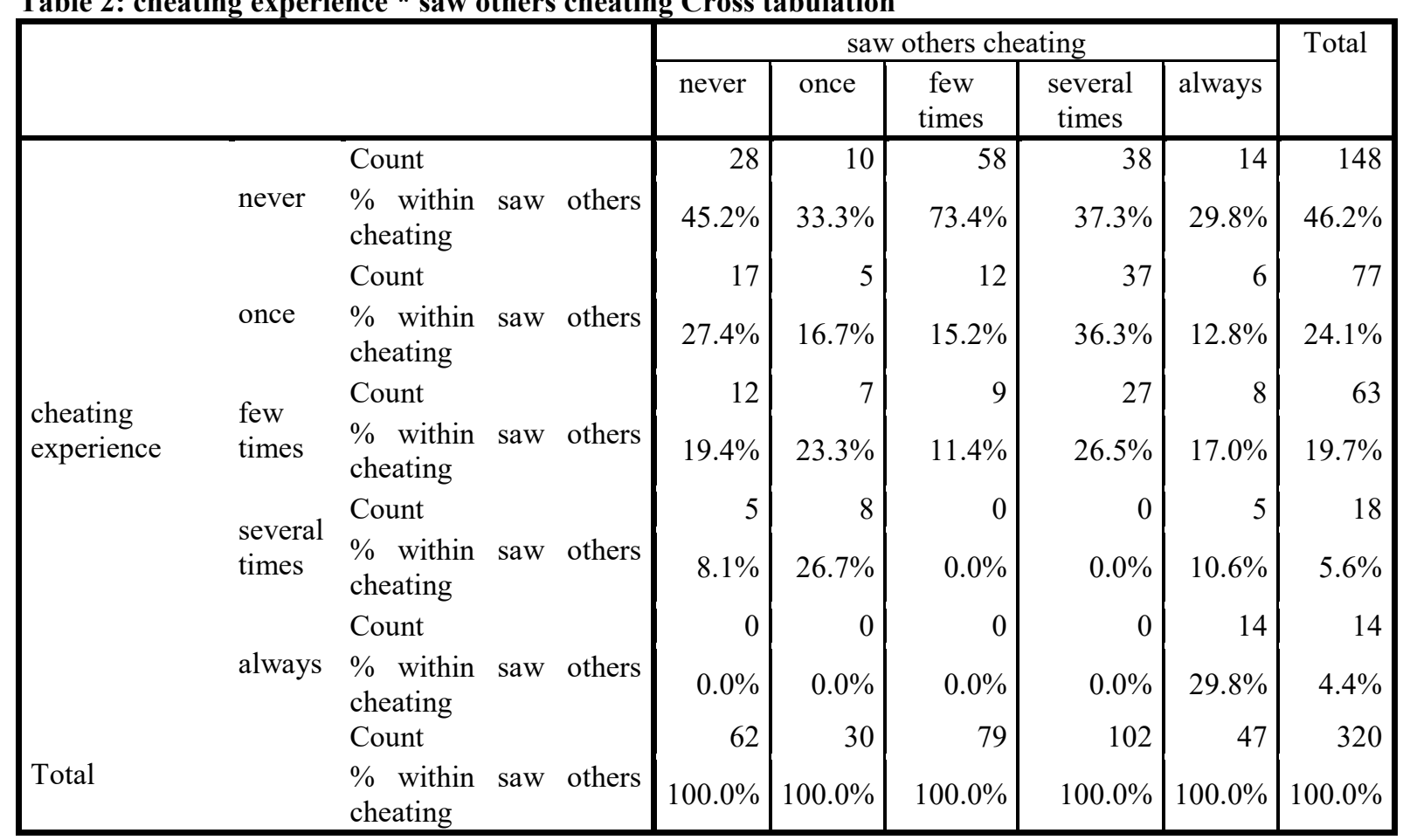

As shown in the table above, as student SGPA increases from below 2.00 to the medium score 2-2.99, the incidences of cheating at least once also increases but decreases as we move to the category of high achievers. The percentage of cheating increases from $16.9 \%$ to 57.5 and decreases to $25.6 \%$ as GPA increases to the highest achievement group. The FGD supports this finding. A participant in the FGD stated that 'the main cause for cheating is desire to score a better grade in a course'. Moreover, findings from the FGD revealed that cheating is understood as a malpractice and is perceived to be serious and prevalent. One participant from main campus, asserted that cheating is a nationwide problem which students indulge into when they are not ready for an exam. Another student revealed that cheating is a widespread abuse in which students are 'stealing marks'. Compared to previous studies, this finding is complemented by some previous findings

while contradicting some others. As studies confirmed, there is a significant negative correlation between 
exam cheating and GPA (Tefera T. \& Kinde G., 2010). The higher the students GPA, the lower the possibility of involving in cheating acts (Crown and Spiller, 1998). The same is partially true as we move to the lower grade category from the medium but not from the medium to the higher. In other words, the higher percentage of cheaters were medium scorers. This complies with what is asserted by Desalegn and Berhan (2014) that the more competent a student is, there is no need to engage in cheating behavior. The prevalence of reported cheating differed by department: Electrical (12.2), Civil (11.6\%) and Management (9.9\%) were the highest self-reported cheating at least one. On the other hand, SWE, chemistry and Economics reported the least cheating.

As shown in table two above, of the $46.25(n=148)$ respondents who never cheated only $45.2 \%(n=28)$ indicated that the never observed others' cheating. On the other hand, $11.62 \%, 12.2 \%, 37.2$ and 19.18\% observed others cheating once, few times, several times and always respectively. When all the respondents are considered, a majority of them $(80.625 \%)$ admitted observing others cheating while only $19.375 \%$ never saw others cheating. Hence, only $8.75(n=28)$ never cheated and never saw others cheating implying that exam cheating is widespread. During the FGD, it was reported that cheating is widespread and frequently observed.

\subsection{Methods of Cheating}

Respondents were asked to determine if and how often they have used any of the cheating methods during written exams. The results indicated that the three most frequent cheating methods used by students include copying from another student by looking at his/her test paper, using electronic devices like phones as cheat aid and passing notes on which answers to questions are written. Of the respondents $38.8 \%$ admitted that they once copy from another student by looking at his/her answers while $15 \%$ reported using these method more than once. This is followed by students using electronic devices either once $(30 \%)$ or more than once $(23.8 \%)$. These findings resemble what has been found in some other studies (cf. Hamzeh M., 2012 \& Philip, 2006).

From the focus group discussion made, it was learned that a number of innovative and traditional methods are used for cheating purposes. A student bitterly indicated that students are innovative when making arrangements for cheating. To put it in FGD participant's words, S3BC stated that :

Students exchange exam booklets, tell answers to those in need of support in students' mother tongue after leaving the exam room.this a bad thing. How can teachers suspect and stop this is difficult.

The least frequently used cheating methods reported are distracting invigilators to help others cheat, writing notes on body parts and writing notes on desks. Of the respondents, $76.6 \%, 71.9 \%$ and $68.8 \%$ never used these methods, respectively.

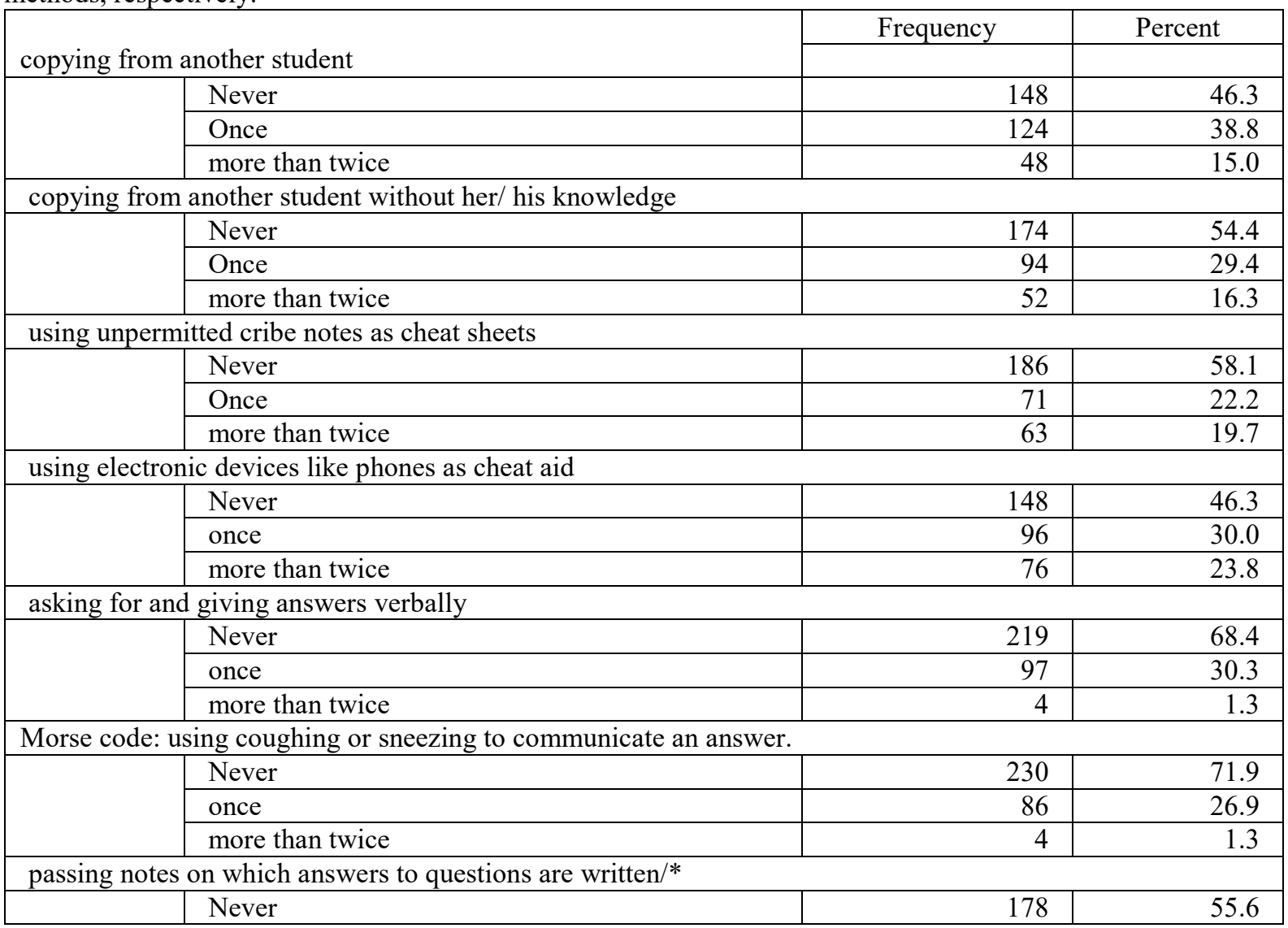




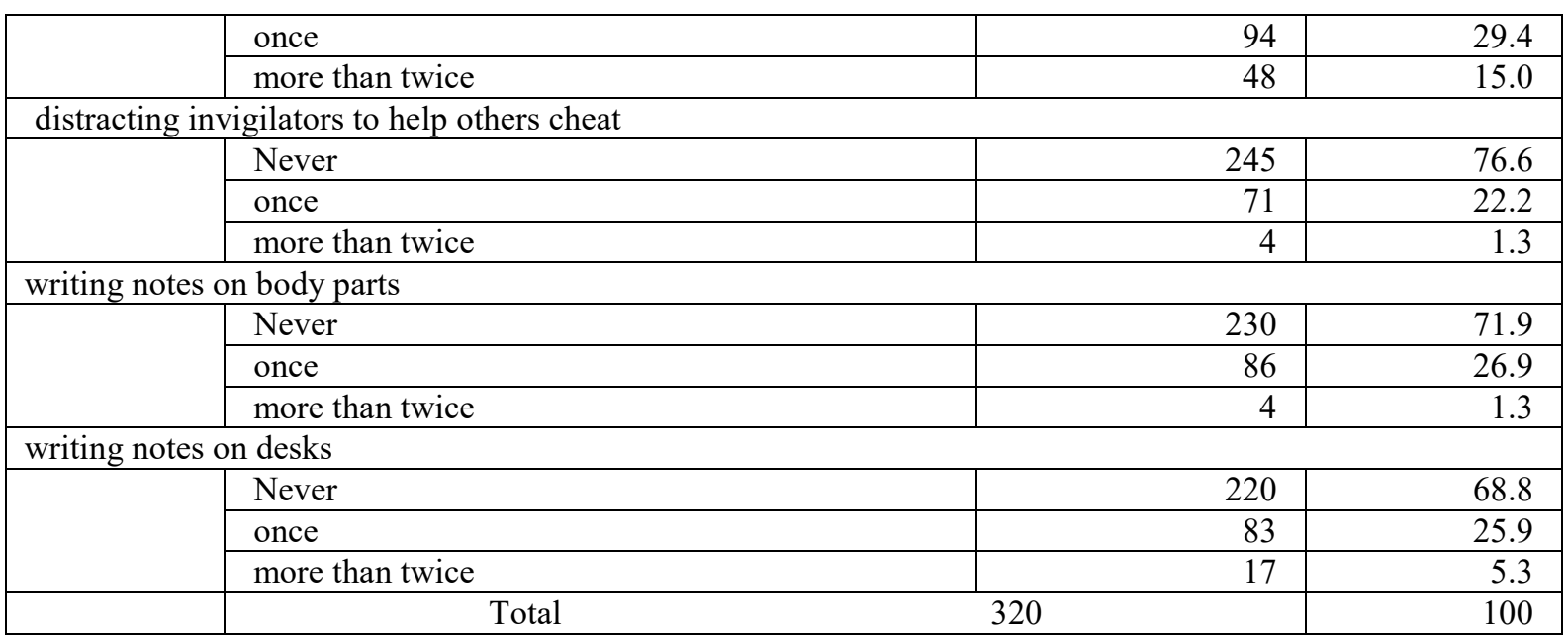

Table 3: Percentages of Students Reporting Each Method of Cheating

\subsection{FACTORS CAUSING EXAM CHEATING}

In the last section of the questionnaire respondents were asked to determine the effect of each of the 20 factors. Table 4. the effect of factors.

\begin{tabular}{|c|c|c|c|c|c|}
\hline \multicolumn{2}{|l|}{ Factors } & \multicolumn{4}{|c|}{ cheating experience } \\
\hline & & \multicolumn{2}{|c|}{ never } & \multicolumn{2}{|c|}{ at least once } \\
\hline & & Count & $\%$ & Count & $\%$ \\
\hline \multirow{5}{*}{$\begin{array}{l}\text { I face time pressure to prepare for } \\
\text { an exam }\end{array}$} & very low & 0 & $0.0 \%$ & 13 & $4.1 \%$ \\
\hline & low & 0 & $0.0 \%$ & 40 & $12.5 \%$ \\
\hline & neutral & 148 & $46.2 \%$ & 0 & $00.0 \%$ \\
\hline & high & 0 & $0.0 \%$ & 54 & $16.9 \%$ \\
\hline & very high & 0 & $0.0 \%$ & 65 & $20.3 \%$ \\
\hline \multirow[t]{5}{*}{ the courses I take are hard } & very low & 0 & $0.0 \%$ & 45 & $14.1 \%$ \\
\hline & low & 0 & $0.0 \%$ & 24 & $7.5 \%$ \\
\hline & neutral & 148 & $46.2 \%$ & 0 & $0.0 \%$ \\
\hline & high & 0 & $0.0 \%$ & 55 & $17.2 \%$ \\
\hline & very high & 0 & $0.0 \%$ & 48 & $15.0 \%$ \\
\hline \multirow[t]{5}{*}{ my own laziness } & very low & $\mathbf{0}$ & $0.0 \%$ & 28 & $8.8 \%$ \\
\hline & low & $\mathbf{0}$ & $0.0 \%$ & 26 & $8.1 \%$ \\
\hline & neutral & 148 & $46.2 \%$ & $\mathbf{0}$ & $0.0 \%$ \\
\hline & high & $\mathbf{0}$ & $0.0 \%$ & 47 & $14.7 \%$ \\
\hline & very high & $\mathbf{0}$ & $0.0 \%$ & 71 & $22.2 \%$ \\
\hline \multirow[t]{5}{*}{ I cheat to Compete with others. } & very low & 0 & $0.0 \%$ & 54 & $16.9 \%$ \\
\hline & low & 0 & $0.0 \%$ & 54 & $16.9 \%$ \\
\hline & neutral & 148 & $46.2 \%$ & 0 & $0.0 \%$ \\
\hline & high & 0 & $0.0 \%$ & 36 & $11.2 \%$ \\
\hline & very high & 0 & $0.0 \%$ & 28 & $8.8 \%$ \\
\hline \multirow{5}{*}{$\begin{array}{l}\text { I cheat to Cope with stress of } \\
\text { studying. }\end{array}$} & very low & 0 & $0.0 \%$ & 77 & $24.1 \%$ \\
\hline & low & 0 & $0.0 \%$ & 40 & $12.5 \%$ \\
\hline & neutral & 148 & $46.2 \%$ & 0 & $0.0 \%$ \\
\hline & high & 0 & $0.0 \%$ & 31 & $9.7 \%$ \\
\hline & very high & 0 & $0.0 \%$ & 24 & $7.5 \%$ \\
\hline \multirow{5}{*}{$\begin{array}{l}\text { I cheat because the exams I take } \\
\text { are hard }\end{array}$} & very low & 0 & $0.0 \%$ & 41 & $12.8 \%$ \\
\hline & low & 0 & $0.0 \%$ & 34 & $10.6 \%$ \\
\hline & neutral & 148 & $46.2 \%$ & 0 & $0.0 \%$ \\
\hline & high & 0 & $0.0 \%$ & 54 & $16.9 \%$ \\
\hline & very high & 0 & $0.0 \%$ & 43 & $13.4 \%$ \\
\hline \multirow{4}{*}{$\begin{array}{l}\text { I cheat because Punishment is not } \\
\text { serious }\end{array}$} & very low & 0 & $0.0 \%$ & 52 & $16.2 \%$ \\
\hline & low & 0 & $0.0 \%$ & 54 & $16.9 \%$ \\
\hline & neutral & 148 & $46.2 \%$ & 0 & $0.0 \%$ \\
\hline & high & 0 & $0.0 \%$ & 45 & $14.1 \%$ \\
\hline
\end{tabular}




\begin{tabular}{|c|c|c|c|c|c|}
\hline & very high & 0 & $0.0 \%$ & 21 & $6.6 \%$ \\
\hline \multirow{5}{*}{$\begin{array}{l}\text { I cheat because I want to improve } \\
\text { my grades }\end{array}$} & very low & 0 & $0.0 \%$ & 40 & $12.5 \%$ \\
\hline & low & 0 & $0.0 \%$ & 34 & $10.6 \%$ \\
\hline & neutral & 148 & $46.2 \%$ & 0 & $0.0 \%$ \\
\hline & high & 0 & $0.0 \%$ & 55 & $17.2 \%$ \\
\hline & very high & 0 & $0.0 \%$ & 43 & $13.4 \%$ \\
\hline \multirow{5}{*}{$\begin{array}{l}\text { I cheat because I get rewards from } \\
\text { peers }\end{array}$} & very low & 0 & $0.0 \%$ & 55 & $17.2 \%$ \\
\hline & low & 0 & $0.0 \%$ & 51 & $15.9 \%$ \\
\hline & neutral & 148 & $46.2 \%$ & 0 & $0.0 \%$ \\
\hline & high & 0 & $0.0 \%$ & 35 & $10.9 \%$ \\
\hline & very high & 0 & $0.0 \%$ & 31 & $9.7 \%$ \\
\hline \multirow{5}{*}{$\begin{array}{l}\text { I cheat because I am forced by } \\
\text { friends }\end{array}$} & very low & 0 & $0.0 \%$ & 52 & $16.2 \%$ \\
\hline & low & 0 & $0.0 \%$ & 46 & $14.4 \%$ \\
\hline & neutral & 148 & $46.2 \%$ & 0 & $0.0 \%$ \\
\hline & high & 0 & $0.0 \%$ & 40 & $12.5 \%$ \\
\hline & very high & 0 & $0.0 \%$ & 34 & $10.6 \%$ \\
\hline \multirow{5}{*}{$\begin{array}{l}\text { I cheat because I am afraid of } \\
\text { failing in the exam }\end{array}$} & very low & 0 & $0.0 \%$ & 34 & $10.6 \%$ \\
\hline & low & 0 & $0.0 \%$ & 39 & $12.2 \%$ \\
\hline & neutral & 148 & $46.2 \%$ & 0 & $0.0 \%$ \\
\hline & high & 0 & $0.0 \%$ & 42 & $13.1 \%$ \\
\hline & very high & 0 & $0.0 \%$ & 57 & $17.8 \%$ \\
\hline \multirow[t]{5}{*}{ I cheat because everybody does it. } & very low & 0 & $0.0 \%$ & 61 & $19.1 \%$ \\
\hline & low & 0 & $0.0 \%$ & 59 & $18.4 \%$ \\
\hline & neutral & 148 & $46.2 \%$ & 0 & $0.0 \%$ \\
\hline & high & 0 & $0.0 \%$ & 27 & $8.4 \%$ \\
\hline & very high & 0 & $0.0 \%$ & 25 & $7.8 \%$ \\
\hline \multirow{5}{*}{$\begin{array}{l}\text { I cheat because the courses I take } \\
\text { are useless. }\end{array}$} & very low & 0 & $0.0 \%$ & 61 & $19.1 \%$ \\
\hline & low & 0 & $0.0 \%$ & 37 & $11.6 \%$ \\
\hline & neutral & 148 & $46.2 \%$ & 0 & $0.0 \%$ \\
\hline & high & 0 & $0.0 \%$ & 40 & $12.5 \%$ \\
\hline & very high & 0 & $0.0 \%$ & 34 & $10.6 \%$ \\
\hline \multirow{5}{*}{$\begin{array}{l}\text { I cheat because my parents wanted } \\
\text { me to pass in the exams }\end{array}$} & very low & 0 & $0.0 \%$ & 60 & $18.8 \%$ \\
\hline & low & 0 & $0.0 \%$ & 55 & $17.2 \%$ \\
\hline & neutral & 148 & $46.2 \%$ & 0 & $0.0 \%$ \\
\hline & high & 0 & $0.0 \%$ & 32 & $10.0 \%$ \\
\hline & very high & 0 & $0.0 \%$ & 25 & $7.8 \%$ \\
\hline \multirow{5}{*}{$\begin{array}{l}\text { I cheat because invigilators } \\
\text { vigilance is poor }\end{array}$} & very low & 0 & $0.0 \%$ & 36 & $11.2 \%$ \\
\hline & low & 0 & $0.0 \%$ & 31 & $9.7 \%$ \\
\hline & neutral & 148 & $46.2 \%$ & 0 & $0.0 \%$ \\
\hline & high & 0 & $0.0 \%$ & 58 & $18.1 \%$ \\
\hline & very high & 0 & $0.0 \%$ & 47 & $14.7 \%$ \\
\hline \multirow[t]{5}{*}{ I cheat because of high course load } & very low & 0 & $0.0 \%$ & 54 & $16.9 \%$ \\
\hline & low & 0 & $0.0 \%$ & 50 & $15.6 \%$ \\
\hline & neutral & 148 & $46.2 \%$ & 0 & $0.0 \%$ \\
\hline & high & 0 & $0.0 \%$ & 38 & $11.9 \%$ \\
\hline & very high & 0 & $0.0 \%$ & 30 & $9.4 \%$ \\
\hline \multirow{5}{*}{$\begin{array}{l}\text { I cheat because I do not want to } \\
\text { take a retest }\end{array}$} & very low & 0 & $0.0 \%$ & 55 & $17.2 \%$ \\
\hline & low & 0 & $0.0 \%$ & 58 & $18.1 \%$ \\
\hline & neutral & 148 & $46.2 \%$ & 0 & $0.0 \%$ \\
\hline & high & 0 & $0.0 \%$ & 41 & $12.8 \%$ \\
\hline & very high & 0 & $0.0 \%$ & 18 & $5.6 \%$ \\
\hline \multirow{5}{*}{$\begin{array}{l}\text { I cheat because the questions are } \\
\text { not understandable }\end{array}$} & very low & 0 & $0.0 \%$ & 53 & $16.6 \%$ \\
\hline & low & 0 & $0.0 \%$ & 58 & $18.1 \%$ \\
\hline & neutral & 148 & $46.2 \%$ & 0 & $0.0 \%$ \\
\hline & high & 0 & $0.0 \%$ & 37 & $11.6 \%$ \\
\hline & very high & 0 & $0.0 \%$ & 24 & $7.5 \%$ \\
\hline
\end{tabular}




\begin{tabular}{|l|l|r|r|r|r|}
\hline \multirow{3}{*}{ I cheat because I lack study skills } & very low & 0 & $0.0 \%$ & 62 & $19.4 \%$ \\
\cline { 2 - 5 } & low & 0 & $0.0 \%$ & 55 & $17.2 \%$ \\
\cline { 2 - 6 } & neutral & 148 & $46.2 \%$ & 0 & $0.0 \%$ \\
\cline { 2 - 6 } & high & 0 & $0.0 \%$ & 32 & $10.0 \%$ \\
\cline { 2 - 6 } & very high & 0 & $0.0 \%$ & 23 & $7.2 \%$ \\
\hline \multirow{3}{*}{$\begin{array}{l}\text { I cheat because I do not attend } \\
\text { class regularly }\end{array}$} & very low & 0 & $0.0 \%$ & 52 & $16.2 \%$ \\
\cline { 2 - 6 } & low & 0 & $0.0 \%$ & 47 & $14.7 \%$ \\
\cline { 2 - 6 } & neutral & 148 & $46.2 \%$ & 0 & $0.0 \%$ \\
\cline { 2 - 6 } & high & 0 & $0.0 \%$ & 43 & $13.4 \%$ \\
\cline { 2 - 6 } & very high & 0 & $0.0 \%$ & 30 & $9.4 \%$ \\
\hline
\end{tabular}

Of the listed factors, time pressure to prepare for an exam, hard Courses, students own laziness, hard exams and poor invigilators vigilance are reported as the most compelling factors forcing students cheat in exams. For instance, $16.9 \%$ and $20.3 \%$ of the respondents indicated that time pressure has a high or very high influence on their cheating while $4.1 \%$ and $12.5 \%$ reported a very low or low influence. Similarly, $18.1 \%$ and $14.7 \%$ of the respondents who admitted cheating at least once reported poor invigilator vigilance highly and very highly causes cheating in exams together with $11.2 \%$ and $9.7 \%$ who reported a very low and low influence, respectively. Moreover, about $17.2 \%$ and $15 \%$ of those who admitted cheating are highly or very highly influenced by difficulty of the courses.

Regarding this S5TC stressed that:

When quality education is not maintained, and time to prepare for exams is insufficient, students cheat. We are given lots of tasks. There are lots of tests and quizzes..... If invigilators sign on a student and then erase it, students will not learn. Similarly only few teachers are serious and take measures on students that cheat. If they do not prepare well, they will cheat. Similarly S2CBE asserted:

Students cheat not to be dismissed. This is one reason. This is worsened by students lacking good background knowledge and study skills. Test difficulty may not be the major reason. Some teachers stand at the gate of the room sometimes. This makes it easy for students to cheat on exams.

Hence, the motivators are a mix of individual and institutional factors comprising the opportunity, desire to succeed, inefectivess t of penalties and reluctance of many invigilators to prosecute (Simkin, \& McLeod, 2009).

On the other end, cheating to cope with stress of studying, cheating because everybody does it and because of lack of study skills are weak predictors. For instance, the percentage of students who are highly and very highly influenced into cheating by stress of studying is $9.7 \%$ and $7.5 \%$ respectively. The percentage of cheating because everybody does it is $9.7 \%$ and $7.5 \%$ who are highly and very highly influenced by this factor while those diverting to cheating because they lack study skills are $10 \%$ (highly) and $7.2 \%$ very highly impacted by the reason. Why courses and exams are hard on students (at least from their perspective)? Many students may not have selected their fields wisely or based on their interest. Another reason for making courses and exams hard is students register a maximum load of courses ( 18 credit hours or more) each semester. Not only this load is above their ability within a semester time, but also it puts a lot of pressure on their schedule to successfully complete many papers, projects, assignments, filed visits, and other academic requirements. Also with this high load, more than one exam is more likely to be on the same day. All these factors make some courses and their exams hard on students.

Table 5: demographic factors

\begin{tabular}{|c|c|c|c|c|c|c|c|}
\hline & & $\mathrm{B}$ & S.E. & Wald & df & Sig. & $\operatorname{Exp}(B)$ \\
\hline \multirow{11}{*}{ Step $1^{\mathrm{a}}$} & College & & & 30.379 & 3 & $.000 *$ & \\
\hline & Technology & .526 & .358 & 2.157 & 1 & 142 & 1.693 \\
\hline & $\mathrm{CBE}$ & 1.553 & .443 & 12.271 & 1 & $.000 *$ & 4.723 \\
\hline & Natural & -.898 & .458 & 3.848 & 1 & .050 & .407 \\
\hline & Bure(reference) & & & & & & \\
\hline & Cheating seen & & & 24.542 & 4 & $.000 *$ & \\
\hline & Never & -.149 & .442 & .113 & 1 & .737 & .862 \\
\hline & Once & .074 & .523 & .020 & 1 & .888 & 1.077 \\
\hline & Few times & -1.615 & .431 & 14.023 & 1 & $.000 *$ & .199 \\
\hline & $\begin{array}{l}\text { Several times } \\
\text { always(reference) }\end{array}$ & -.140 & .399 & .124 & 1 & .725 & .869 \\
\hline & Constant & .209 & .440 & .225 & 1 & 635 & 1.232 \\
\hline
\end{tabular}

From the above table showing significant demographic factors, students in CBE are more likely (odd ratio= 
4.7) to cheat as compared to students in Bure campus while students in the CNCS are less likely (odd ratio=0.407) to cheat at $95 \%$ confidence level. Similarly, students who saw others cheating few times are less likely to cheat as compared to those who saw others cheating always. Meanwhile there is no significant difference in the probability of cheating of those who never see others cheat and those who always see others cheat. This might imply that students seeing others cheat not negatively punished decide to do the same themselves.

\subsection{Preventing Cheating in Exams}

Quantitative data in this study has shown that exam cheating is widespread and serious problem. The research also affirms that very few students are caught cheating and very little has been done by the university and individual instructors to prevent cheating. Therefore, it might be imperative to conclude by paying attention to what can be done to prevent cheating in exams. Accordingly, the FGDs and interviews were meant to uncover possible exam cheating prevention and detection strategies.

Above all, it should be clear that cheating harms not only the cheaters but all partners of the academic community, including students, instructors, the university, and the society at large and thence an integrated approach that can curb the situation should be designed. In line with this, preventing exam cheating should be seen as part of the nationwide effort for quality education.

Preventing Exam cheating should be an integrated and sustained effort involving three aspects of the practice. These efforts include cheating prevention(before the exam), cheating detection (during the exam) \& cheating data retention-archiving (after the exam) participating all parties. These would create an atmosphere where success by cheating is unlikely and futile (Philip C. H. , 2006). In the first place, it has been observed that instructors rarely discuss rules of academic dishonesty, its consequences and side effects with their students though cheating has become widespread. Before taking any practical action to prevent cheating, students should understand an important baseline. They should "understand that cheating is offensive to all a teacher stands for and that our basic motivation for going into teaching as a profession is offended when students cheat" (Moss, 1984:2).

In addition, students should know the institutional rules and policy regarding academic dishonesty and the consequences of cheating. They should know that it is very likely that their invigilator will strongly react to any kind of breach. Concerning this, a student in the main cumpus asserted that:

Even if the students know that cheating in an exam is a bad thing, I don't think they clearly know its

bad effects at all. If they know, they are harming themselves when they cheat, the cheater would never

try it. Cheating can't make you a clever student.

Thus, one long lasting strategy to curb this malpractice can be creating an environment where cheating or academic dishonesty is unacceptable (Philip C. H. , 2006). As of S1CBE:

The students should realize that a score out of cheating can never have a lasting significance.

Moreover, they should develop a negative attitude towards cheating. They can cooperate during

preparation but they should expose cheaters. They should not tolerate it.

Moreover, test item preparation, invigilation room and inivigilators assignment should meet basic requirments. As of the FGD carried out multiple choice items are suited for cheating. Hence, though we couldn't remove such items from an exam, it is plausible to take other remedial measures. The number of students in an exam hall and their seat allotment should not be haphazard (Philip C. H. , 2006). Pertaining this, S3BC from the FGD discussants suggested that:

Most teachers simply get into the class and distribute exam papers.they do not check our IDs. They

do not even know if students agree and sit together. So they don't check and arrange our seat.

When students are sitting closer they can see another students answer even when they do not want to cheat especially choice items.

These implies that a number of things can be done to reduce students propensity to cheat before the exams are admisistered. S7CNC asserted that:

Some students SMS answers but teachers rarely request us to siwitch of our mobiles. Even notes on a sheet of paper or on their hands or on desks. I can tell you one student who shouted answers in his mother tongue. All this can be reduced if students work hard from the lower level onwards and teachers focus on helping students in the classroom.

Preparing fair exams and grading students fairly also has a significant effect (Genereux\& McLeod, 1995) which according to the FGD and questionnaire is a major factor for cheating. Awaring invigilators about the traditional and innovative methods of cheating and safeguarding exam hall area can be a good move.

Having clear expectations and arrangements both out side and in the exam hall, several things could be done to detect the acts of cheating. Teachers should be empowered to detect exam cheating practices. Using serious and effective invigilation, and using multiple invigilators and methods rather than depending only on exams can reduce cheating (Philip C. H. , 2006). With regard to this FGD participants unanimously stated that invigilators awareness of cheating methods and vigiliance are major factors to detect cheaters. For instance S4TC underlined that:

Most of the time the invigilating teachers sit at the back or front of the room. They also stand at the 
gate. Sometimes, they take out their smart phones may be play games or using social media.Some

move around the class.

While it might be boring and quite unlikely to be alert, for instance in a three hours exam, it must be seen as a critical moment in a course. Invigilatars should remain attentive through out the exam session. As for making cheating as difficult as possible during the exams, the punishment of commiting it should become severe and unwavering (Genereux\& McLeod, 1995). Once a malpractice is cxommited, it is important to take appropriate action against the offender. However, students fretfully reported that measures taken on cheaters are too inconsistent and ineffectual. Regarding this, student S3BC from Bure campus stressed that:

Some students caught cheating are forgiven frequently and this is having a negative effect. Students

never learn from this. They instead assume that they will be forgiven all the time.

In addition, all students' cheating actions should be reported to a central record-keeping office to help identify repeated offenders (Todd-Mancillas\& Sisson, 1987) which according to the legislation and disciplinary rules would result in taking more serious measures thereby forcing students to refrain from cheating.

\section{CONCLUSIONS AND RECOMMENDATIONS}

\subsection{Conclusions}

The purpose of this study has been assessing factors that persuade students to cheat and recommend possible strategies to prevent and detect it. Specifically, the study intended to the identify prevalence of exam cheating, factors that force students to cheat, exam cheating strategies that students' use and prevention and detection strategies. This research used mixed methods sequential explanatory design (Creswell, 2011). Accordingly, the following conclusions are drawn.

1. The study uncovered that more than half of the sampled students cheat during written exams at least once. The overall percentage of students admitted cheating in written exams in the semester was 53.75\%. On the basis of the self-reported exam cheating, of those who admitted cheating at least once, about $59 \%$ have a Semester Grade Point Average of 2.00-3.00 implying that cheating might have improved achievement.

2. The findings indicated that the three most frequent cheating methods used by students include copying from another student by looking at his/her test paper, using electronic devices like phones as cheat aid and passing notes on which answers to questions are written. The least frequently used cheating methods reported are distracting invigilators to help others cheat, writing notes on body part s and writing notes on desks. Of the respondents, $76.6 \%, 71.9 \%$ and $68.8 \%$ never used these methods, respectively.

3. Relating to factors, time pressure to prepare for an exam, hard Courses, students own laziness, hard exams and poor invigilators vigilance are reported as the most compelling factors forcing students cheat in exams. On the other end, cheating to cope with stress of studying, cheating because everybody does it and because of lack of study skills are weak predictors.

4. The FGD carried out and analysis of data from the questionnaire indicates that a number of strategies are not enacted to survive the challenge. Course load and the resulting time pressure along with difficulty of exams and courses has intensified exam cheating. Creating awareness for invigilators about exam cheating prevention and detection is a step towards the solution. Integrated efforts involving students should be made to curb exam cheating

\subsection{Recommendations}

In the light of the study results and the previous discussion about exam cheating behavior of students, the following recommendations are made.

A drastic measure based on integrated approaches has to be enacted to prevent and detect exam cheating. First, students need to be oriented, when they start their study, about the University policy regarding academic cheating in general and cheating in exams in particular so that they would partner in the fight against exam cheating. Second, invigilation situations and settings should be strengthened to control and prohibit any cheating behaviors. More concern should be considered to multiple-choice tests especially in large class sizes. Third, students should know that cheating behaviors will not be tolerated by their instructors and the University administration. Finally, students cheatings should be documented and attached to their profiles consistently to serve as refrences in case of repreated misbehavior. Moreover, professional development opportunities should be created for staff members, especially about the innovative cheating methods.

\section{References}

Adeyemi, T. (2010). Examination Malpractices among Secondary Schools Students in Ondo State, Nigeria: Perceived Causes and Possible Solutions.American-Eurasian Journal of Scientific Research 5 (1): 67-75

Anton, D. L., \& Michael, W. B. (1983). Short-term predictive validity of demographic, affective, personal, and cognitive variables in relation to criterion measures of cheating behaviors. Educational and Psychological 
Measurement, 43, 467-483.

Brimble, M. \& Stevenson-Clarke, P. (2005). Perceptions of the prevalence and seriousness of academic dishonesty in Australian University, Australian educational researchers, 32 (3), 19-44.

Creswell, J., (2011). Designing and Conducting Mixed Methods Research. (2nd ed.). Thousand Oaks, CA: Sage

Desalegn, A. and Berhan, A. (2014). Cheating on examinations and its predictors among undergraduate students at Hawassa UniversityCollege of Medicine and Health Science, Hawassa, Ethiopia. Accessed on November 2, 2015 from http://www.biomedcentral.com/1472-6920/14/89.

Israel, Glenn D. (2009). Determining Sample Size. IFAS, University of Florida. Accessed on 28 December, 2015 from: https://edis.ifas.ufl.edu/pdffiles/PD/PD00600.pdf

MebratuMulatuBachore (2014). Academic Dishonesty/ Corruption in the Period of Technology: Its implication for Quality of Education.” American Journal of Educational Research, vol. 2, no. 1 1): 1060 1064.

McCabe, D. L. (2003). Academic Integrity Rutgers University Student Survey. Accessed on 15October2015. https://honesty.rutgers.edu/rutgers.asp

McCabe, D. L., \& Trevino, L.K. (1997). Individual and contextual influences on academic dishonesty: A multicampus investigation. Research in Higher Education, 38, 379-396.

Ministry of Education (MoE). (2005 E.C). The harmonized academic policy of Higher Education Institutions. Addis Ababa.

Philip C. H. (2006). How College Students Cheat On In-Class Examinations: Creativity, Strain, and Techniques of Innovation. M Publishing, University of Michigan.

Simkin, M. \& McLeod, A. (2009). Why Do College Students Cheat? Journal of Business Ethics. Springer, DOI $10.1007 / s 10551-009-0275-x 13 p$

Taderera, E., Nyikahadzoi , L., Matamande W., \&Mandimika E.,(UD).Exploring management strategies to reduce cheating in written examinations: case study of Midlands State University. Journal of Case Studies in Education. Accessed on October 01 from www.aabri.com/manuscripts/131528.pdf

Teixeira, A.C. \& Rocha, M.F. (2006). Academic cheating in Austria, Portugal, Romania and Spain, Journal of Research and International Education, 1 (3), 198-209.

Tefera T. \& Kinde G. (2010). An Exploration of UndergraduateStudents' Self-Reported Academic Dishonesty at Addis Ababa and JimmaUniversities.Ethiopian. Journal of. Education and Science 5(2), 79-98.

\section{Limitations of the study}

In this study, document analysis was planned as a source of data to identify reported incidences vis a vis measures taken on exam cheating. However, since such documents are not centrally documented and readily available, the researcher exempted the method. Instructors views on the issue is not considered. Moreover, though the researcher made efforts to assure students about anonymity of the data they give, the issue of cheating might have worried respondents and thus, cautions should be taken in the findings of this self reported exam cheating research. 